\title{
Management of Persistent Hyponatremia after Off-Pump Coronary Artery Bypass Grafting: A Case Report
}

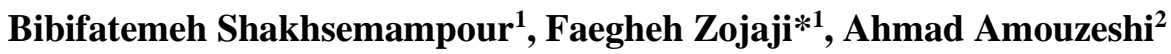

1. Department of Anesthesiology, Birjand University of Medical Sciences, Birjand, Iran

2. Department of Cardiac Surgery and Cardiovascular Diseases Research Center, Birjand University of Medical Sciences, Birjand, Iran

\begin{abstract}
Background: Delayed hyponatremia is a common phenomenon following transsphenoidal surgery. Recent evidence suggests that the risk of developing intensive care unit-acquired hyponatremia is high following cardiac surgery. Herein, we report management of persistent hyponatremia after offpump coronary artery bypass in a patient with diabetes and hypothyroidism who was on diuretics.

Case description: An 81-year-old man with diabetes and hypothyroidism was admitted to Valiasr hospital in Birjand (Iran) with history of typical chest pain and dyspnea since a month ago. Coronary angiography revealed a critical triple vessel disease, and therefore, the patient was considered a candidate for coronary artery bypass grafting. His pre-operative sodium level was normal but decreased to $128 \mathrm{mEq} / \mathrm{L}$ on sixth postoperative day.

Conclusion: When hyponatremia is detected in a patient with hypothyroidism, even if severe, in the absence of myxedema coma, it may not be directly associated with the lack of thyroid hormones. Thus, other possible etiologies should be considered.
\end{abstract}

KEYWORDS: Persistent hyponatremia, CABG, Management

\section{Received: 2019/02/25 $\quad$ Revised: 2019/04/15 $\quad$ Published:2019/05/25}

*Correspondence: Faegheh Zojaji, Department of Anesthesiology, Birjand University of Medical Sciences, Birjand, Iran

Tel: +98-9155631706

Email: s.daliri44@gmail.com 


\section{INTRODUCTION}

Electrolyte abnormalities including hyponatremia and hypernatremia are common problems in adult hospitalized patients. These conditions are associated with hospital mortality rates ranging from $42 \%$ to $60 \%$ (3). Fluid and serum electrolyte disturbance and sodium imbalance may develop after any neurosurgical procedure. Pituitary surgery is especially well known to cause diabetes insipidus and hyponatremia $(1,4)$. Intensive care unit (ICU)-acquired hyponatremia and hypernatremia are particularly common among critically ill post-cardiac surgery patients (5). Hypothyroidism-associated hyponatremia may occur following diuretics use and can be accompanied with comorbid conditions such as cardiovascular diseases and diabetes mellitus (6). Hyponatremia is generally defined as a serum sodium concentration of less than $135-136 \mathrm{mEq} / \mathrm{L}$ and can be categorized into two types: dilutional hyponatremia and depletional hyponatremia (3). Severe hyponatremia is associated with high morbidity and mortality rates e.g. a serum sodium concentration of less than 105 $\mathrm{mEq} / \mathrm{L}$ has a mortality risk of $50 \%$ (2).

Symptoms related to hyponatremia varies widely ranging from moderately severe (cognitive impairments and gait disturbance) to severe or life-threatening (hypoxemia, coma and epilepsy). Treatment strategies for hyponatremia differ according to the severity of clinical symptoms and duration of the condition $(7,8)$. Administration of hypertonic saline solution must be performed with extreme caution since excessively slow or rapid sodium correction can have severe neurologic side effects (7). Hypertonic saline plus a loop diuretic is the treatment of choice for patients presenting severe symptoms and those with acute symptomatic hyponatremia (9). The goal of asymptomatic hyponatremia treatment is to avoid further decline of serum sodium level and to maintain sodium levels in the normal range as much as possible (9). Herein, we report management of persistent hyponatremia after off-pump coronary artery bypass in a patient with diabetes and hypothyroidism who was on diuretics.

\section{CASE PRESENTATION}

An 81-year-old man with diabetes and hypothyroidism was admitted to Valiasr hospital in Birjand (Iran) with history of typical chest pain and dyspnea since a month ago. He had difficulty breathing [New York heart association (NYHA) class II] in the past four months. Diastolic dysfunction was noted in 2-dimensional echocardiogram. Coronary angiography revealed a critical triple vessel disease, and therefore, the patient was considered a candidate for coronary artery bypass grafting (CABG). $\mathrm{He}$ was under treatment with furosemide (20 $\mathrm{mg}$ BID), losartan (12.5 mg daily), levothyroxine (25 mcg daily), intravenous $0.9 \%$ saline (2 liters daily), insulin and heparin (2500 unit BID). His pre-operative complete blood count, coagulation parameters, serum blood urea nitrogen, creatinine, $\mathrm{Na}$ and $\mathrm{K}$ levels were within normal range. He underwent off-pump coronary artery bypass (OPCAB) with grafting of the left anterior descending, posterior descending, diagonal and obtuse marginal arteries. After the $\mathrm{CABG}$, the patient was transferred to the ICU. Vital signs, urine output, urine and serum electrolyte levels and hematological parameters were checked every six hours. Serum sodium level decreased $(128 \mathrm{mEq} / \mathrm{l})$ after six days. There was no clinical symptom. Urine and serum osmolality, serum thyroid-stimulating hormone, T4, T3, serum albumin, serum uric acid and urinary sodium concentration were evaluated (Table 1). 
Table 1. Results of the laboratory tests

\begin{tabular}{|c|c|c|c|c|c|c|c|c|c|c|}
\hline $\begin{array}{c}\mathbf{T S H} \\
(\boldsymbol{\mu l} \mathbf{l} / \mathbf{m L})\end{array}$ & $\begin{array}{c}\mathbf{T 4} \\
(\mathbf{n m o l} / \mathbf{L})\end{array}$ & $\begin{array}{c}\mathbf{T 3} \\
(\mathbf{n m o l} / \mathbf{L})\end{array}$ & $\begin{array}{c}\text { Serum } \\
\mathbf{a l b u m i} \\
\mathbf{n}(\mathbf{g} / \mathbf{L})\end{array}$ & $\begin{array}{c}\text { Uric } \\
\mathbf{a c i d} \\
(\mathbf{m g} / \mathbf{d L})\end{array}$ & $\begin{array}{c}\text { Urine } \\
\mathbf{0 s m o l a l i t y} \\
(\mathbf{m O s m} / \mathbf{K} \\
\mathbf{g})\end{array}$ & $\begin{array}{c}\text { Serum } \\
\mathbf{u r e a} \\
(\mathbf{m g} / \mathbf{m L})\end{array}$ & $\begin{array}{c}\text { Serum } \\
\text { creatinin } \\
\mathbf{e} \\
(\mathbf{m g} / \mathbf{m L})\end{array}$ & $\begin{array}{c}\text { Serum } \\
\mathbf{0 s m o l a l i t y} \\
(\mathbf{m O s m} / \mathbf{K g})\end{array}$ & $\begin{array}{c}\text { Serum } \\
\mathbf{N a} \\
(\mathbf{m e q} / \mathbf{L})\end{array}$ & $\begin{array}{c}\text { Urine } \\
\mathbf{N a} \\
(\mathbf{m c q} / \mathbf{d})\end{array}$ \\
\hline 5.66 & 3.55 & 0.976 & 3 & 2.4 & 1105 & 17 & 0.7 & 278.9 & 133 & 491 \\
\hline
\end{tabular}

After consulting with an internist, losartan and furosemide were discontinued and dose of levothyroxine was increased to $50 \mathrm{mcg}$ daily. The patient received hypertonic saline (5\%) infusion, $15 \mathrm{cc}$ per hour (high dose) and serum electrolytes were checked every three hours. Vital signs, urine output, and urine and serum osmolality were checked at the end of each nursing shift. Mean level of serum sodium was $122 \mathrm{mEq} / \mathrm{L}$ during the treatment. The patient was stable after 17 days of hospitalization and remained stable in the regular follow ups after discharge for one year. Table 2 presents the level of serum sodium during the hospitalization period.

Table 2. Serum sodium concentrations during the postoperative hospitalization period

\begin{tabular}{|c|c|c|c|c|c|c|c|c|c|c|c|c|c|c|c|c|c|}
\hline $\begin{array}{c}\text { Postoperative } \\
\text { day }\end{array}$ & 1 & 2 & 3 & 4 & 5 & 6 & 7 & 8 & 9 & 10 & 11 & 12 & 13 & 14 & 15 & 16 & 17 \\
\hline $\mathrm{Na}(\mathrm{mEq} / \mathbf{L})$ & 133 & 129 & 131 & 133 & 130 & 124 & 117 & 118 & 119 & 124 & 122 & 124 & 127 & 129 & 131 & 135 & 136 \\
\hline
\end{tabular}

\section{DISCUSSION}

Delayed hyponatremia is a common phenomenon following transsphenoidal pituitary surgery (1). Recent evidence suggests that the risk of developing ICUacquired hyponatremia is higher than hypernatremia following cardiac surgery (2). ICU-acquired hyponatremia and hypernatremia are also common complications of cardiac surgery (5). The etiology of hyponatremia in patients who had undergone transsphenoidal surgery is debated. The most common cause of delayed postoperative hyponatremia is syndrome of inappropriate antidiuretic hormone secretion (1).

Cases of hypothyroidism-induced hyponatremia often have comorbid conditions such as cardiovascular diseases and diabetes mellitus (6). Diuretics use is one of the most common causes of severe hyponatremia (10). Hypothyroidism is associated with significant changes in renal function, including hypoosmolar hyponatremia (11). Fluid restriction and hormone replacement therapy can quickly correct hyponatremia (11).

In our case, hypothyroidism as well as losartan and furosemide use resulted in resistant hypoosmolar hyponatremia, which led us to discontinue losartan and furosemide and prescribe levothyroxine at a higher dose. The patient also received hypertonic saline therapy for correction of persistent hyponatremia.

There is little known about the incidence and outcomes of sodium disturbances as they occur in a large unselected population of critically ill patients after cardiac surgery (5). The most effective way to reduce the risk of hyponatremia is to allow patients resume or control their own fluid intake and electrolyte balance as soon as safely possible. Further studies are required to establish optimal strategies for monitoring, diagnosing and managing ICU-acquired sodium disturbances and controlling diuretics use in ill patients. 


\section{CONCLUSION}

Hyponatremia can occur in patients with hypothyroidism, but no definitive relationship has been demonstrated between the two conditions. Detection of hyponatremia in a patient with hypothyroidism, even if severe, in the absence of myxedema coma, may not be directly associated with the lack of thyroid hormones; thus, other possible etiologies should be considered.

\section{DECLARATIONS}

\section{Funding}

Not applicable.

\section{Ethics approvals and consent to participate}

Oral consent was obtained from the subject and he was assured that his personal data will remain confidential.

\section{Conflict of interest}

The authors declare that there is no conflict of interest regarding the publication of this article.

\section{REFERENCES}

1. LEE JI, Cho WH, Choi BK, Cha SH, Song GS, Choi $\mathrm{CH}$. Delayed hyponatremia following transsphenoidal surgery for pituitary adenoma. Neurologia medico-chirurgica. 2008;48(11):48994. [DOI:10.2176/nmc.48.489]

2. Stelfox HT, Ahmed SB, Khandwala F, Zygun D, Shahpori R,Laupland K. The epidemiology of intensive care unit-acquiredhyponatraemia and hypernatraemia in medical-surgical intensive 3. care units. Critical care. 2008; 12(6): R162. [DOI:10.1186/cc7162]

4. Bagshaw SM, Townsend DR, McDermid RC. Disorders of sodium and water balance in hospitalized patients. Canadian Journal of Anesthesia/Journal canadien d'anesthésie. 2009 Feb 1;56(2):151-67 [DOI:10.1007/s12630-0089017-2]

5. Loh JA, Verbalis JG. Disorders of water and salt metabolism associated with pituitary disease. Endocrinology and metabolism clinics of North America. 2008;37(1):213-34. [DOI:10.1016/j.ecl.2007.10.008]
6. Stelfox HT, Ahmed SB, Zygun D, Khandwala F, Laupland K. Characterization of intensive care unit acquired hyponatremia and hypernatremia following cardiac surgery. Canadian Journal of Anesthesia/Journal canadien d'anesthésie. 2010;57(7):650-8. [DOI:10.1007/s12630-0109309-1]

7. Waikar SS, Mount DB, Curhan GC. Mortality after hospitalization with mild, moderate, and severe hyponatremia. The American journal of medicine. 2009;122(9):857-65. [DOI:10.1016/j.amjmed.2009.01.027]

8. Bohl MA, Ahmad S, White WL, Little AS. Implementation of a postoperative outpatient care pathway for delayed hyponatremia following transsphenoidal surgery. Neurosurgery. 2017;82(1):110-7. [DOI:10.1093/neuros/nyx151]

9. Barkhoudarian G, Kelly DF. Complications with Transsphenoidal Surgery: A Review. In Transsphenoidal Surgery 2017 (pp. 315-343). Springer, Cham. [DOI:10.1007/978-3-319-566917_19]

10. Sterns RH, Nigwekar SU, Hix JK. The treatment of hyponatremia. Seminars in nephrology. 2009; 29(3): 282-299. [DOI:10.1016/j.semnephrol.2009.03.002]

11. Liamis G, Milionis H, Elisaf M. A review of drug-induced hyponatremia. American journal of kidney diseases. 2008;52(1):144-53. [DOI:10.1053/j.ajkd.2008.03.004]

12. Gross P. Treatment of hyponatremia. Internal Medicine. 2008;47(10):885-91. [DOI:10.2169/internalmedicine.47.0918] 